\title{
Persistência e Fitotoxicidade do Herbicida Atrazine Aplicado na Cultura do Milho Sobre a Cultura do Girassol em Sucessão ${ }^{1}$
}

\author{
Persistence and Phytotoxicity of the Herbicide Atrazine Applied on Corn Crop on Successive \\ Sunflower Crop
}

\author{
BRIGHENTI, A.M. ${ }^{2}$, MORAES, V.J. ${ }^{3}$, OLIVEIRA JR., R.S. ${ }^{4}$, GAZZIERO, D.L.P. ${ }^{2}$, VOLL, E. ${ }^{2}$ e \\ GOMES, J.A. ${ }^{5}$
}

\begin{abstract}
RESUMO - Embora o herbicida atrazine aplicado na cultura do milho seja seletivo para esta cultura, pode causar fitotoxicidade em cultivos em sucessão/rotação. Dois experimentos foram conduzidos em campo, a fim de avaliar o efeito residual do herbicida atrazine aplicado na cultura do milho sobre a cultura do girassol em sucessão. Um deles foi conduzido no município de Montividiu-GO e o outro em Londrina-PR. O delineamento experimental foi o de blocos casualizados em parcelas subdivididas. Intervalos entre a aplicação do herbicida atrazine na cultura do milho e a semeadura da cultura do girassol foram dispostos nas parcelas, e as doses de atrazine aplicadas na cultura do milho, nas subparcelas. Em Montividiu, o girassol foi semeado aos 90, 116 e 128 dias após a aplicação (DAA) das doses de 0 (testemunha sem aplicação), 1,5 e 2,5 $\mathrm{kg} \mathrm{ha}^{-1}$ de atrazine. Em Londrina, o girassol foi semeado aos 60, $90 \mathrm{e}$ 120 DAA das doses de 0 (testemunha sem aplicação), 3,0 e 6,0 $\mathrm{kg} \mathrm{ha}^{-1}$ de atrazine. A produtividade da cultura do girassol sofreu reduções significativas, em função dos resíduos de atrazine na semeadura realizada aos 60 dias após a aplicação das doses de 3,0 e 6,0 kg ha-1. Nenhuma das características avaliadas na cultura do girassol foi afetada significativamente pelos resíduos do herbicida quando a semeadura foi realizada aos 90, 116, 120 e 128 dias após a aplicação das doses de atrazine na cultura do milho em ambos os locais estudados.
\end{abstract}

Palavras-chave: resíduos, triazinas, Helianthus annuus.

\begin{abstract}
Although the herbicide atrazine applied on the corn crop is selective to this crop it can cause phytotoxicity in sensitive/rotational crops. Two experiments were carried out under field conditions to evaluate the residual effect of atrazine, applied on corn crop, on successive sunflower crop. One experiment was conducted in Montividiu, Goiás - Brazil and the other in Londrina, Paraná- Brazil. The experiments were arranged in a split-plot design in randomized complete blocks. Intervals between atrazine application on the corn crop and sunflower sowing were as the plots and atrazine rates sprayed on the corn crop the subplots. In Montividiu, sunflower was sowed at 90, 116 and 128 days after atrazine application (DAA) at the rates of $O$ (untreated control), 1.5 and $2.5 \mathrm{~kg} \mathrm{ha}^{-1}$. In Londrina, sunflower was sowed 60, 90 and $120 \mathrm{DAA}$ at the rates of $O$ (untreated control), 3.0 and $6.0 \mathrm{~kg} \mathrm{ha}{ }^{-1}$. Sunflower yield was significantly reduced by atrazine residues (3.0 and $6.0 \mathrm{~kg} \mathrm{ha}^{-1}$ ) at $60 \mathrm{DAA}$. None of the sunflower characteristics was significantly affected by atrazine residues when sowing was conducted at 90,116, 120 and 128 days after atrazine application on corn crop in both experiments.
\end{abstract}

Key words: residue, triazine, Helianthus annuus.

\section{INTRODUÇÃO}

Em razão da grande área cultivada no Brasil, da escassez e do alto custo de mão-de- obra no meio rural, o uso de herbicidas vem aumentando de maneira acentuada. Dependendo das condições edafoclimáticas e das características químicas das moléculas dos

1 Recebido para publicação em 23/8/2001 e na forma revisada em 7/8/2002.

2 Pesquisador-Embrapa Soja, Caixa Postal 231, 86970-001, Londrina-PR. ${ }^{3}$ Eng.-Agr. Coordenador de Pesquisa - Área Herbicidas - Milênia Agro Ciências, Caixa Postal 2025, Londrina-PR. ${ }^{4}$ Prof. Adjunto - Universidade Estadual de Maringá. Av. Colombo, 5790, 87020-900 Maringá-PR. ${ }^{5}$ Prof. Adjunto - Universidade Federal de Goiás, Caixa Postal 03, 75800-000 Jataí-GO. 
herbicidas, estes poderão permanecer ativos no solo por longo período, podendo afetar o desenvolvimento de culturas subseqüentes (Anderson, 1983). A presença desses resíduos além do período útil, ou seja, o período de competição das plantas daninhas, é indesejável porque não somente provoca injúrias às culturas em rotação/sucessão, mas também pode atingir niveis que afetariam o desenvolvimento de microrganismos do solo e a contaminação do lençol freático (Victória Filho, 1982; Bushway et al., 1992). Segundo Blanco et al. (1983), a persistência dos herbicidas no solo depende da natureza química, da formulação, das doses aplicadas do produto, das características do solo e dos fatores climáticos do meio. Por essas razões, informações obtidas em determinados locais, quando extrapoladas para outras regiões, de solo e clima diferentes, apresentam sempre valor relativo.

Diversos herbicidas, que apresentam longo efeito residual no solo, estão sendo utilizados em larga escala no Brasil, dentre os quais se destaca o atrazine, recomendado para a cultura do milho. Controla, principalmente, espécies daninhas de folhas largas e algumas gramíneas (Rodrigues \& Almeida, 1998). Entretanto, esse produto pode causar sérios prejuízos em culturas semeadas em sucessão.

Em relação ao girassol, a cultura é sensível a diferentes herbicidas, destacando-se o imazaquin e o imazethapyr (Fleck \& Vidal, 1994; Vidal \& Fleck, 1994), o atrazine (Castro et al., 1997; Rossi, 1998), o clomazone (Vidal \& Fleck, 1993) e, em menor grau, o chlorimuron-ethyl (Fleck \& Vidal, 1993).

Em razão de o intervalo entre a aplicação do herbicida atrazine no milho e a semeadura do girassol, em condições de safrinha, ser mais curto que nos casos normais de rotação de culturas, casos de injúrias químicas podem ocorrer, devido ao efeito residual do princípio ativo desse produto. Além disso, esse intervalo pode ser menor ainda quando o agricultor colhe o milho para silagem e semeia, em seguida, o girassol.

O objetivo deste trabalho foi avaliar o efeito residual do herbicida atrazine aplicado na cultura do milho sobre o girassol semeado em sucessão.

\section{MATERIAL E MÉTODOS}

Dois experimentos foram conduzidos em campo, sendo o primeiro instalado em área de cultivo da Fazenda Brasilanda, município de Montividiu-GO, e o segundo em área experimental da Embrapa Soja, Londrina-PR. Os solos onde foram conduzidos os experimentos, em Montividiu e Londrina, são classificados como Latossolo Vermelho-Amarelo e Latossolo Roxo distrófico, respectivamente, cujas análises física e química encontram-se na Tabela 1.

O delineamento experimental foi o de blocos casualizados em parcelas subdivididas, com cinco repetições no experimento de Montividiu e quatro repetições no de Londrina. Nas parcelas foi semeado o girassol em três épocas, e nas subparcelas foram aplicadas as doses de atrazine na cultura do milho. No experimento instalado em Montividiu, as datas de semeadura do girassol foram 14/2/00, 11/3/ 00 e 23/3/00, correspondentes a 90, 116 e 128 dias após a aplicação (DAA) das doses de 0 (testemunha), 1,5 e 2,5 kg ha-1. Em Londrina, as datas de semeadura foram 18/12/00, 15/ $1 / 01$ e 18/2/01, correspondentes a 60, 90 e 120 DAA das doses de 0 (testemunha), 3,0 e $6,0 \mathrm{~kg} \mathrm{ha}^{-1}$ de atrazine.

Tabela 1 - Resultados das análises física e química do solo, para a camada de 0-20 cm, da área experimental. Embrapa Soja, Londrina-PR, 2001는

\begin{tabular}{|l|c|c|c|c|c|c|c|c|c|c|c|c|c|c|}
\hline \multirow{2}{*}{ Município } & Argila & Silte & Areia & $\mathrm{MO}$ & $\mathrm{P}$ & $\begin{array}{c}\mathrm{PH} \\
\mathrm{CaCl}_{2}\end{array}$ & $\mathrm{~K}$ & $\mathrm{Ca}$ & $\mathrm{Mg}$ & $\mathrm{H}+\mathrm{Al}$ & $\mathrm{SB}$ & $\mathrm{CTC}$ & $\mathrm{V}$ \\
\cline { 2 - 28 } & \multicolumn{3}{|c|}{$\left(\mathrm{g} \mathrm{kg}^{-1}\right)$} & $(\%)$ & $\left(\mathrm{mg} \mathrm{dm}^{-3}\right)$ & & \multicolumn{5}{|c|}{$\left(\mathrm{cmol}_{\mathrm{c}} \mathrm{dm}^{-3}\right)$} & \\
\hline Montividiu & 633,2 & 122,5 & 244,2 & 3,4 & 9,60 & 5,44 & 0,43 & 2,81 & 1,00 & 3,88 & 4,24 & 8,12 & 52,22 \\
\hline Londrina & 770,0 & 156,0 & 74,0 & 2,8 & 28,5 & 5,45 & 0,56 & 4,56 & 2,07 & 4,37 & 7,19 & 11,56 & 62,20 \\
\hline
\end{tabular}

${ }^{1 /}$ Resultados fornecidos pelo Laboratório de Análise de Solo e Tecido Vegetal da Embrapa Soja. 
A cultura do milho foi implantada em semeadura direta no experimento de Montividiu em 16 de novembro de 1999, utilizando o híbrido Cargill 901, no espaçamento de 0,90 m, com cinco sementes por metro linear. A área das parcelas foi de $112 \mathrm{~m}^{2}(16 \times 7 \mathrm{~m})$, e a das subparcelas, de $28 \mathrm{~m}^{2}$ (4 x $\left.7 \mathrm{~m}\right)$, sendo a área útil destinada às avaliações de $12,6 \mathrm{~m}^{2}$. A adubação de semeadura foi constituída de $300 \mathrm{~kg} \mathrm{ha}^{-1}$ de NPK (7-23-9) e $40 \mathrm{~kg} \mathrm{ha}^{-1} \mathrm{de}$ nitrogênio (200 $\mathrm{kg} \mathrm{ha}^{-1}$ de sulfato de amônio), em cobertura. No experimento de Londrina, o milho foi implantado em semeadura convencional em 13 de outubro de 2000 , utilizando o cultivar BRS 4150 no espaçamento de $0,90 \mathrm{~m}$, com cinco sementes por metro linear. A área das parcelas foi de $113,4 \mathrm{~m}^{2}(16,2 \times 7 \mathrm{~m})$ e a das subparcelas de $37,8 \mathrm{~m}^{2}(5,4 \times 7 \mathrm{~m})$, sendo a área útil destinada às avaliações de $16,2 \mathrm{~m}^{2}$. A adubação de semeadura foi constituída de $350 \mathrm{~kg} \mathrm{ha}^{-1}$ de NPK (5-20-20) e $40 \mathrm{~kg} \mathrm{ha}^{-1} \mathrm{de}$ nitrogênio (200 kg ha-1 de sulfato de amônio), em cobertura.

A aplicação das doses do herbicida foi feita após a semeadura do milho, em condições de pré-emergência da cultura. Em Montividiu, essa operação foi realizada no mesmo dia e logo após a semeadura, utilizando pulverizador costal à pressão constante, mantida por $\mathrm{CO}_{2}$ comprimido, de $276 \mathrm{kPa}$, equipado com barra de $2,5 \mathrm{~m}$ de largura e seis bicos de jato plano AI 110-015, distanciados de $0,5 \mathrm{~m}$, com volume de pulverização equivalente a $170 \mathrm{~L} \mathrm{ha}^{-1}$. A temperatura do ambiente era de $23{ }^{\circ} \mathrm{C}$ e a umidade relativa do ar de $78 \%$, com solo úmido na superfície e velocidade do vento de $4 \mathrm{~km} \mathrm{~h}^{-1}$.

Em Londrina, a aplicação do herbicida foi realizada em 17/10/01, utilizando pulverizador costal à pressão constante, mantida por $\mathrm{CO}_{2}$ comprimido, de $276 \mathrm{kPa}$, equipado com barra de 2,5 $\mathrm{m}$ de largura e seis bicos de jato plano BD 110-015, distanciados de 0,5 m, com volume de pulverização equivalente a $150 \mathrm{~L} \mathrm{ha}^{-1}$. Por ocasião da aplicação do produto, a temperatura do ambiente era de $26{ }^{\circ} \mathrm{C}$ e a umidade relativa do ar, de $67 \%$, com solo úmido na superfície e velocidade do vento de $6 \mathrm{~km} \mathrm{~h}^{-1}$.

A cada época de semeadura, o milho era cortado e instalada a cultura do girassol. Em ambos os experimentos foi utilizado o cultivar de girassol Morgan 742 em semeadura direta. O espaçamento da cultura no experimento de
Montividiu foi de $0,7 \mathrm{~m}$, com 3 sementes por metro linear. A adubação do girassol foi feita com $300 \mathrm{~kg} \mathrm{ha}^{-1}$ de NPK (8-20-18). Em Londrina, foi utilizado o espaçamento de $0,90 \mathrm{~m}$ com 4 sementes por metro linear, e a adubação de semeadura foi constituída de $350 \mathrm{~kg} \mathrm{ha}^{-1}$ de NPK (5-20-20). Aos 30 dias após cada semeadura, foi realizada, em ambos os experimentos, uma adubação em cobertura com $40 \mathrm{~kg}$ de nitrogênio ha ${ }^{-1}$ e aplicado boro, via foliar, na dosagem de 1,2 kg de $\mathrm{B} \mathrm{ha}^{-1}$.

Foram obtidos os valores médios do diâmetro do caule e do capítulo a partir da medição de dez plantas escolhidas ao acaso dentro de cada subparcela. O peso de mil aquênios foi obtido por meio da pesagem em balança graduada. O teor de óleo foi determinado através de ressonância magnética nuclear, com equipamento NMR, marca Oxford, modelo 4000. A produtividade da cultura foi determinada a partir da avaliação de três linhas de girassol de $6 \mathrm{~m}$ de comprimento na área útil das subparcelas, em ambos os experimentos, e realizada a transformação em $\mathrm{kg} \mathrm{ha}^{-1}$.

Os dados obtidos foram submetidos à análise de variância, sendo as médias comparadas pelo teste de Tukey a 5\% de probabilidade.

\section{RESULTADOS E DISCUSSÃO}

Com o intuito de reduzir a possibilidade de injúrias causadas por herbicidas que apresentam longo período residual, são sugeridos intervalos de segurança maiores. Isso dificulta a implantação de culturas na época de safrinha. Rossi (1998), por exemplo, recomenda um intervalo de 180 dias entre a aplicação do herbicida atrazine no milho e a semeadura do girassol. No entanto, a persistência do atrazine é bastante influenciada pelas características do solo. Esse processo é tanto maior quanto mais elevados forem os teores de argila e matéria orgânica (Weber et al., 1969; Reinhardt et al., 1990; Jenks et al., 1998). Sua degradação é essencialmente microbiana, sendo os principais compostos resultantes do metabolismo a desisopropilatrazine, a desetilatrazine e a hidroxiatrazine (Muir \& Baker, 1978; Brouwer et al., 1990). Dessa forma, condições de alta temperatura e precipitações típicas do sudoeste de Goiás e do norte do Estado do Paraná podem favorecer a intensificação da 
atividade microbiana e, conseqüentemente, a degradação mais rápida do atrazine.

As variáveis diâmetro de caule e de capítulo, peso de mil aquênios e teor de óleo não foram influenciadas pelas doses de atrazine em nenhuma das épocas de semeadura do girassol para ambos os experimentos (Tabelas 2 e 3). Com relação à produtividade da cultura, não foram verificadas reduções nos valores obtidos, em função das doses de atrazine nas três épocas de semeadura do girassol no experimento conduzido no município de Montividiu-GO (Tabela 2). As doses aplicadas em Montividiu foram menores que aquelas aplicadas em Londrina, e, a partir dos 90 DAA, o resíduo desse herbicida não mais afetou o girassol. Segundo Rodrigues \& Almeida (1998), doses recomendadas de atrazine podem persistir por períodos de cinco a sete meses em condições tropicais e subtropicais. Entretanto, a concentração total do resíduo do produto no solo, em determinada época, não significa que essa quantidade esteja totalmente disponivel e capaz de prejudicar os cultivos em sucessão (Reinhardt \& Nel, 1993). Delmonte et al. (1996) avaliaram a persistência do atrazine por meio de bioensaios com aveia em três tipos de solos da região de Buenos Aires. Foi verificado que a persistência do herbicida, na dose recomendada, variou de 100 a 221 dias após a aplicação do produto, de acordo com as características dos solos utilizados. Reinhardt (1995) avaliou a persistência do atrazine, após a aplicação de seis doses do produto na cultura do milho, em solos da África do Sul e verificou redução na produtividade do girassol após 12 meses da aplicação desse herbicida.

Aos 60 DAA das doses de atrazine no experimento de Londrina, o herbicida ainda persistia no solo em quantidades capazes de reduzir a produtividade do girassol (Tabela 3). Na testemunha sem aplicação foram obtidos $2.708,3 \mathrm{~kg} \mathrm{ha}^{-1}$, enquanto nas doses de 3,0 e $6,0 \mathrm{~kg} \mathrm{ha}^{-1}$ foram alcançados $2.316,0 \mathrm{e}$ $2.162,7 \mathrm{~kg} \mathrm{ha}^{-1}$, respectivamente. Esses valores foram estatisticamente semelhantes, porém diferindo da testemunha. Essa redução da produtividade correspondeu, em relação à testemunha, a 392,3 e 545,6 $\mathrm{kg} \mathrm{ha}^{-1}$ para as doses de 3,0 e 6,0 kg ha ${ }^{-1}$, respectivamente. No entanto, a partir dos 90 DAA, o herbicida não mais afetou essa característica. A data de semeadura correspondente a 90 dias após a aplicação das doses do atrazine é importante para os agricultores que planejam cultivar o milho a fim de obter silagem e, na sucessão, semear o girassol no período de safrinha. Utilizando esse planejamento, o intervalo entre as aplicações do atrazine no milho e a semeadura do girassol é menor quando comparado com aquele em que se objetiva colher o milho como grão.

Tabela 2 - Diâmetro de caule (mm), diâmetro de capítulo (cm), peso de mil aquênios (PMA) (g), teor de óleo (\%) e produtividade da cultura do girassol $\left(\mathrm{kg} \mathrm{ha}^{-1}\right)$, em função da aplicação das doses do herbicida atrazine $\left(\mathrm{kg} \mathrm{ha}^{-1}\right)$, em três épocas de semeadura do girassol, em Montividiu-GO. Embrapa Soja, Londrina-PR, 2001

\begin{tabular}{|c|c|c|c|c|c|c|c|}
\hline $\begin{array}{c}\text { Data da } \\
\text { semeadura }\end{array}$ & $\begin{array}{l}\text { Dias após a } \\
\text { aplicação do } \\
\text { herbicida }\end{array}$ & Dose & $\begin{array}{l}\text { Diâmetro de } \\
\text { caule }\end{array}$ & $\begin{array}{l}\text { Diâmetro de } \\
\text { capítulo }\end{array}$ & PMA & $\begin{array}{l}\text { Teor de } \\
\text { óleo }\end{array}$ & Produtividade \\
\hline \multirow{3}{*}{ 14/fev./00 } & \multirow{3}{*}{90} & 0 & $16,00 \mathrm{~A}^{1 /}$ & $17,78 \mathrm{~A}$ & $56,83 \mathrm{~A}$ & $45,17 \mathrm{~A}$ & $1.857,19 \mathrm{~A}$ \\
\hline & & 1,5 & $16,50 \mathrm{~A}$ & $15,90 \mathrm{~A}$ & $56,87 \mathrm{~A}$ & $44,70 \mathrm{~A}$ & $1.866,63 \mathrm{~A}$ \\
\hline & & 2,5 & $15,60 \mathrm{~A}$ & $16,92 \mathrm{~A}$ & $56,23 \mathrm{~A}$ & $44,76 \mathrm{~A}$ & $1.799,05 \mathrm{~A}$ \\
\hline \multirow{3}{*}{ 11/mar./00 } & \multirow{3}{*}{116} & 0 & $16,38 \mathrm{~A}$ & $13,10 \mathrm{~A}$ & $51,16 \mathrm{~A}$ & $41,87 \mathrm{~A}$ & $980,34 \mathrm{~A}$ \\
\hline & & 1,5 & $14,36 \mathrm{~A}$ & $12,04 \mathrm{~A}$ & $47,54 \mathrm{~A}$ & $43,24 \mathrm{~A}$ & $809,07 \mathrm{~A}$ \\
\hline & & 2,5 & $15,10 \mathrm{~A}$ & $13,10 \mathrm{~A}$ & $50,95 \mathrm{~A}$ & $42,68 \mathrm{~A}$ & $854,16 \mathrm{~A}$ \\
\hline \multirow{3}{*}{ 23/mar./00 } & \multirow{3}{*}{128} & 0 & $12,48 \mathrm{~A}$ & $9,74 \mathrm{~A}$ & $42,56 \mathrm{~A}$ & $45,30 \mathrm{~A}$ & $299,04 \mathrm{~A}$ \\
\hline & & 1,5 & $13,44 \mathrm{~A}$ & $10,64 \mathrm{~A}$ & $41,70 \mathrm{~A}$ & $45,52 \mathrm{~A}$ & $369,43 \mathrm{~A}$ \\
\hline & & 2,5 & $12,20 \mathrm{~A}$ & $10,12 \mathrm{~A}$ & $39,83 \mathrm{~A}$ & $45,61 \mathrm{~A}$ & $344,59 \mathrm{~A}$ \\
\hline $\mathrm{CV}(\%)$ & - & - & 9,89 & 10,51 & 6,06 & 1,38 & 18,66 \\
\hline DMS & - & - & 2,29 & 2,20 & 4,72 & 1,97 & 300,60 \\
\hline
\end{tabular}

${ }^{1 /}$ Em cada coluna e para cada data de semeadura, as médias seguidas pela mesma letra não diferem entre si pelo teste de Tukey a $5 \%$ de probabilidade. 
A disponibilidade dos resíduos de atrazine é diferente de solo para solo e pode explicar a variação de danos causados em cultivos sensíveis (Reinhardt \& Nel, 1993). Solos mais argilosos e/ou com maiores teores de matéria orgânica podem favorecer a persistência desse produto. Também, a quantidade de chuvas e as variações de temperaturas ocorridas em anos diferentes podem afetar a velocidade de degradação do atrazine no solo (Sheets, 1970). O período durante a condução dos experimentos foi bastante chuvoso, exceto os meses de maio e junho de 2000 em Montividiu (Figuras 1 e 2). Essa disponibilidade de água no solo pode ter favorecido a degradação do produto em ambas as regiões.

Tabela 3 - Diâmetro de caule (mm), diâmetro de capítulo (cm), peso de mil aquênios (PMA) (g), teor de óleo (\%) e produtividade da cultura do girassol $\left(\mathrm{kg} \mathrm{ha}^{-1}\right)$, em função da aplicação das doses do herbicida atrazine $\left(\mathrm{kg} \mathrm{ha}^{-1}\right)$, em três épocas de semeadura do girassol, em Londrina-PR. Embrapa Soja, Londrina-PR, 2001

\begin{tabular}{|c|c|c|c|c|c|c|c|}
\hline $\begin{array}{c}\text { Data da } \\
\text { semeadura }\end{array}$ & $\begin{array}{c}\text { Dias após a } \\
\text { aplicação do } \\
\text { herbicida }\end{array}$ & Dose & $\begin{array}{c}\text { Diâmetro de } \\
\text { caule }\end{array}$ & $\begin{array}{c}\text { Diâmetro de } \\
\text { capítulo }\end{array}$ & PMA & $\begin{array}{c}\text { Teor de } \\
\text { óleo }\end{array}$ & Produtividade \\
\hline & & 0 & $25,30 \mathrm{~A}^{\underline{1}}$ & $21,60 \mathrm{~A}$ & $67,59 \mathrm{~A}$ & $40,32 \mathrm{~A}$ & $2.708,39 \mathrm{~A}$ \\
& 60 & 3 & $26,50 \mathrm{~A}$ & $22,45 \mathrm{~A}$ & $63,87 \mathrm{~A}$ & $39,41 \mathrm{~A}$ & $2.316,04 \mathrm{~B}$ \\
& & 6 & $26,30 \mathrm{~A}$ & $21,52 \mathrm{~A}$ & $63,27 \mathrm{~A}$ & $39,55 \mathrm{~A}$ & $2.162,76 \mathrm{~B}$ \\
\hline & & 0 & $21,07 \mathrm{~A}$ & $18,02 \mathrm{~A}$ & $64,38 \mathrm{~A}$ & $41,21 \mathrm{~A}$ & $2.006,03 \mathrm{~A}$ \\
$15 /$ jez./00 & 90 & 6 & $21,37 \mathrm{~A}$ & $18,67 \mathrm{~A}$ & $68,25 \mathrm{~A}$ & $40,74 \mathrm{~A}$ & $2.085,81 \mathrm{~A}$ \\
& & 0 & $17,32 \mathrm{~A}$ & $15,45 \mathrm{~A}$ & $56,82 \mathrm{~A}$ & $40,61 \mathrm{~A}$ & $1.109,30 \mathrm{~A}$ \\
& 120 & 3 & $18,07 \mathrm{~A}$ & $15,85 \mathrm{~A}$ & $54,80 \mathrm{~A}$ & $42,56 \mathrm{~A}$ & $1.159,61 \mathrm{~A}$ \\
\hline & & 6 & $17,60 \mathrm{~A}$ & $16,60 \mathrm{~A}$ & $54,90 \mathrm{~A}$ & $41,40 \mathrm{~A}$ & $1.153,10 \mathrm{~A}$ \\
\hline CV $(\%)$ & - & - & 9,76 & 7,32 & 5,42 & 5,09 & 11,07 \\
\hline DMS & - & - & 3,30 & 2,38 & 7,00 & 3,75 & 336,88 \\
\hline
\end{tabular}

1/ Em cada coluna e para cada data de semeadura, as médias seguidas pela mesma letra não diferem entre si pelo teste de Tukey a $5 \%$ de probabilidade.

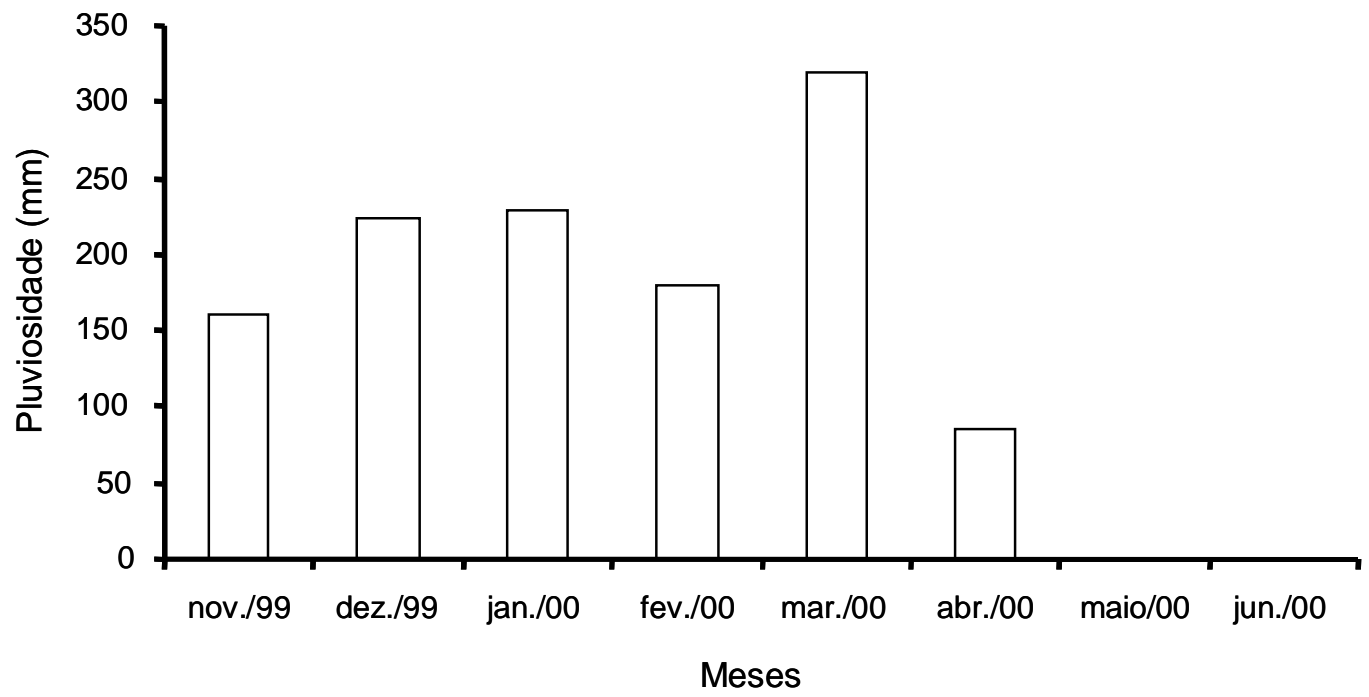

Figura 1 - Pluviosidade mensal ocorrida no período de novembro de 1999 a junho de 2000, no município de Montividiu-GO. Embrapa Soja, Londrina-PR, 2001. 


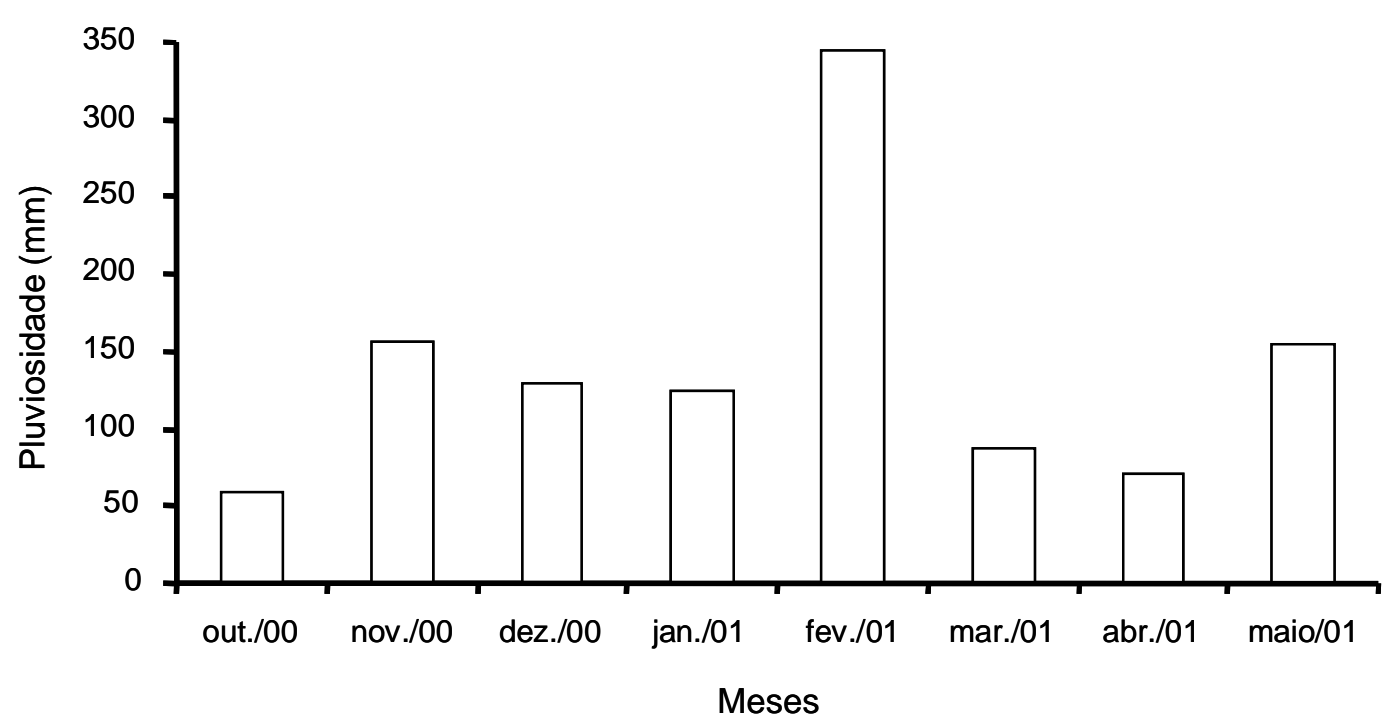

Figura 2 - Pluviosidade mensal ocorrida no período de outubro de 2000 a maio de 2001, no município de Londrina-PR. Embrapa Soja, Londrina-PR, 2001.

Conclui-se que, nesses tipos de solos e nas condições estudadas, o girassol semeado aos 60 dias após a aplicação do herbicida sofreu reduções significativas na produtividade. No entanto, nenhuma das características avaliadas na cultura do girassol foi afetada significativamente pelos resíduos do herbicida quando a semeadura foi realizada aos 90, 116, 120 e 128 dias após a aplicação das doses do produto na cultura do milho.

\section{AGRADECIMENTOS}

Aos proprietários, Eng.-Agr. Marion Kompier e Wilhelmus H.J. Kompier, e aos técnicos da Fazenda Brasilanda, Ariston Ermes Vieira e Lázaro Francisco Alves. Ao técnico agrícola da Milênia Agro Ciências, Divino Sérgio Ferreira, pela colaboração. Aos técnicos agrícolas da Embrapa Soja, Mário Nakano, Reinaldo Moriyama, Roberval Fagundes e Esmael da Silva.

\section{LITERATURA CITADA}

ANDERSON, W. P. Weed science: principles. 2.ed. New York: West Publishing, 1983. 655 p.

BLANCO, H. G. et al. Persistência do herbicida metribuzin em solos cultivados com soja. Pesq. Agropec. Bras., v. 18, p. 1073-1084, 1983.
BROUWER, W. W. M.; BOESTEN, J. J. T. I.; SIEGERS, W. G. Adsorption of transformation products of atrazine by soil. Weed Res., v. 30, p. 123-128, 1990.

BUSHWAY, R. J. et al. Atrazine, alachlor, and carbofuran contamination of well water in Central Maine. Bull.

Environ. Contam. Toxicol., v. 49, p. 1-9, 1992.

CASTRO, C. et al. A cultura do girassol. Londrina: EMBRAPA - CNPSo, 1997. 36 p. (EMBRAPA - CNPSo. Circular Técnica, 13).

DELMONTE, A. A. et al. Persistence of the biocide activity of atrazine in soils of the southeast of Buenos Aires province. Planta Daninha, v. 14, p. 110-117, 1996.

FLECK, N. G.; VIDAL, R. A. Injúria potencial de herbicidas de solo ao girassol. II Chlorimuron-ethyl. Planta Daninha, v. 11, p. 44-48, 1993.

FLECK, N. G.; VIDAL, R. A. Injúria potencial de herbicidas de solo ao girassol. III Imazaquin e imazethapyr. Planta Daninha, v. 12, p. 39-43, 1994.

JENKS, B. M.; ROETH, F. W.; MARTIN, A. R. Influence of surface and subsurface soil properties on atrazine sorption and degradation. Weed Sci., v. 46, p. 132-138, 1998.

MUIR, D. C. G.; BAKER, B. E. The disappearance and movement of three triazine herbicides and several of their degradation products in soil under field conditions. Weed Res., v. 18, p. 111-120, 1978.

REINHARDT, C. F. Residual effect of atrazine on fieldgrown dry beans and sunflower. S. Afr. J. Plant Soil, v. 12, p. 82-85, 1995. 
REINHARDT, C. F.; EHLERS, J. G.; NEL, P. C.

Persistence of atrazine as affected by selected soil properties. S. Afr. J. Plant Soil, v. 7, p. 182-187, 1990.

REINHARDT, C. F.; NEL, P. C. Variable tolerance of some crop species to atrazine in various soils. S. Afr. J. Plant Soil, v. 10, p. 183-187, 1993.

RODRIGUES, B. N.; ALMEIDA, F. S. Guia de herbicidas. 4.ed. Londrina: Edição do Autor, 1998. 648 p.

ROSSI, R. O. Girassol. Curitiba: R.O. Rossi, 1998. 333 p.

SHEETS, T. J. Persistence of triazine herbicides in soils. Resid. Rev., v. 32, p. 287-310, 1970.
VIDAL, R. A.; FLECK, N. G. Injúria potencial de herbicidas de solo ao girassol. I Clomazone. Planta Daninha, v. 11, p. 36-43, 1993.

VIDAL, R. A.; FLECK, N. G. Injúria potencial de herbicidas de solo ao girassol. IV Rendimento de aquênios e componentes do rendimento. Planta Daninha, v. 12, p. 44-51, 1994.

VICTÓRIA FILHO, R. Controle de plantas daninhas. In: CREA-SP. Controle integrado de plantas daninhas. São Paulo: 1982. p. 77-89.

WEBER, J. B.; WEED, S. B.; WARD, T. M. Adsorption of s-triazines by soil organic matter. Weed Sci., v. 17, p. 417420, 1969 . 